\title{
Granulocyte Macrophage Colony-Stimulating Factor in 66 Patients with Myeloid or Lymphoid Neoplasms and Recipients of Hematopoietic Stem Cell Transplantation with Invasive Fungal Disease
}

\author{
Amar Safdar ${ }^{a}$ b Gilhen Rodriguez $^{\mathrm{a}} \quad$ Jorge Zuniga $^{\mathrm{a}}$ Fadi Al Akhrass $^{\mathrm{a}}$ \\ Georgia Georgescu ${ }^{a}$ Anupam Pande ${ }^{a}$

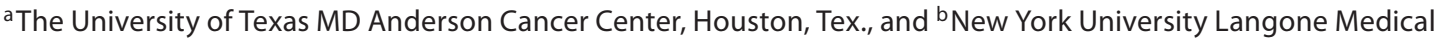 \\ Center, New York, N.Y., USA
}

\begin{abstract}
Key Words
Invasive fungal disease $\cdot$ Granulocyte macrophage colony-stimulating factor $\cdot$ Stem cell transplant $\cdot$ Leukemia $\cdot$ Combination antifungal agents $\cdot$ Immune suppression
\end{abstract}

\begin{abstract}
Background/Aims: Adding granulocyte macrophage colony-stimulating factor (GM-CSF) may improve the response to antifungal therapy in immunosuppressed patients with invasive fungal disease (IFD). Methods: We retrospectively assessed 66 patients in whom GM-CSF was given during antifungal therapy. Results: Severe neutropenia (77\%) and refractory/relapsed cancer (65\%) were common in the group. Prior to GM-CSF therapy, $15 \%$ of patients received high-dose corticosteroids for a median of $30 \pm 16$ days [median cumulative dose (c.d.) 1,184 $\pm 1,019 \mathrm{mg}$, and 9 received steroids during GM-CSF therapy for a median of $16 \pm 12$ days (median c.d. $230 \pm 1,314 \mathrm{mg}$ ). Mild toxic effects were noted in $9 \%$ of patients; there were no cases of cardiopulmonary toxicity. All-cause deaths were observed in $68 \%$ of patients and $48 \%$ died of progressive IFD. High-dose corticosteroids prior to GM-CSF (OR 24; 95\% Cl 2.21-264.9; $\mathrm{p} \leq$ 0.009), GM-CSF started in the intensive care unit (OR 10; $95 \% \mathrm{Cl} 1.66-63.8$;
\end{abstract}

$\mathrm{p} \leq 0.01)$, concurrent granulocyte transfusions (OR $5 ; 95 \% \mathrm{Cl}$ 1.27-16.8; $\mathrm{p} \leq 0.02$ ) and proven/probable IFD (OR $4 ; 95 \% \mathrm{Cl}$ $1-16.2 ; \mathrm{p} \leq 0.05$ ) predicted antifungal treatment failure. Conclusions: GM-CSF adjuvant therapy was tolerated without serous toxicity and antifungal treatment failure remained a challenge in patients treated with high-dose systemic corticosteroids.

Copyright $\odot 2012$ S. Karger AG, Basel

\section{Introduction}

Treatment of invasive fungal disease (IFD) remains difficult in severely immunosuppressed patients with leukemia or lymphoma [1] and in patients following allogeneic hematopoietic stem cell transplantation [2]. To improve treatment, researchers have explored the use of recombinant cytokines such as recombinant human granulocyte macrophage colony-stimulating factor (GM-CSF) and interferon-gamma (IFN- $\gamma$ ) to improve the hosts' immune control of these life-threatening opportunistic infections

A restricted educational grant from Bayer Pharmaceuticals was awarded to the principal investigator (A.S.) and used in part for this study.

\section{KARGER}

Fax +4161306 1234

E-Mail karger@karger.ch

www.karger.com
(C) 2012 S. Karger AG, Basel

$0001-5792 / 13 / 1291-0026 \$ 38.00 / 0$

Accessible online at:

www.karger.com/aha
Assoc. Prof. Amar Safdar, MD

Transplant Infectious Diseases, New York University Langone Medical Center New York University School of Medicine

550 First Avenue, HW-1649B, New York, NY 10016 (USA)

E-Mail amar.safdar@ nyumc.org 
[3]. In immunosuppressed animals, GM-CSF alone or in combination with IFN- $\gamma$ has been shown to enhance the fungicidal activity of innate phagocytic cells $[4,5]$. Furthermore, treating human neutrophils ex vivo with GMCSF with or without IFN- $\gamma$ has been shown to promote fungicidal activity against Rhizopus and Absidia species hyphae [6]; whereas without such an immune 'boost,' neutrophils are largely ineffective against germinating Rhizopus hyphae, a prominent agent of human mucormycosis [6]. Interestingly, IFN- $\gamma$ alone was recently shown to have a modest impact in an experimental model of disseminated Rhizopus species infection and only when GM-CSF was added to IFN- $\gamma$, a prolonged survival and reduced fungal tissue burden occurred in mice [7]. Improved immune control following cytokine therapy has also been demonstrated for the emerging black molds such as Scedosporium apiospermum $[8,9]$ and Scedosporium prolificans. A differential efficacy in the optimal duration of GM-CSF exposure for promoting fungicidal activity of neutrophils against these two species of Scedosporium was an interesting finding in this study [10]; however, the clinical relevance of this observation remains uncertain.

Clinical data on the use of GM-CSF as adjuvant antifungal therapy are scarce; occasional case reports [11] or small case series of 2-8 patients, mostly with drug-refractory invasive aspergillosis, fusariosis, zygomycosis or Scedosporium species infection, have been published but provide limited information [12-15]. Large case series are critically needed to assess the role of therapeutic safety and more importantly efficacy of GM-CSF in patients with established invasive fungal disease before feasibility of prospective trial(s) can be considered.

We previously showed that large GM-CSF doses (median $4,750 \mu \mathrm{g}$ ) can be safely administered to cancer patients with refractory neutropenia who are also receiving healthy-donor granulocyte transfusions plus IFN- $\gamma$ for drug-refractory IFD. More than half of these patients had improvement and/or stabilization of life-threatening fungal disease [16]. Here, we present a comprehensive analysis of a substantial cohort of patients with cancer and/or allogeneic hematopoietic stem cell transplantation who developed refractory IFD and received adjuvant GM-CSF.

\section{Materials and Methods}

Study Design

We retrospectively analyzed all consecutive patients who had hematological malignancies and/or had undergone allogeneic hematopoietic stem cell transplantation and who had received GM-
CSF (sargramostim) as adjuvant immune enhancement therapy for IFD at the University of Texas MD Anderson Cancer Center (Houston, Tex., USA) between July 2000 and January 2007. The study was undertaken after obtaining approval from the institutional review board; the requirement for written informed consent was waived. Patients were followed until early 2010 for delayed GM-CSF adverse events, infection recurrence and all-cause mortality. Patients were identified using the institutional pharmacy database and data were collected from electronic medical records. These helped to identify patients in whom fungal disease occurred during GM-CSF prophylaxis and in whom GM-CSF was added as salvage adjuvant with progressive fungal disease. Data collected included demographic information, underlying cancer, comorbid conditions, history and type of stem cell transplantation, types of infections and outcomes.

The treatment response was determined by the following: (a) treating primary hematologist or bone marrow transplant faculty; (b) consulting infectious diseases and pulmonary faculty, when present; (c) reports from the institutional radiology department and microbiology laboratory, and (d) all treatment responses including deaths associated with progressive invasive fungal disease were independently reassessed by the study team and the principle investigator.

\section{Definitions}

IFD was defined as proven, probable or possible according to the guidelines of the Invasive Fungal Infections Cooperative Group of the European Organization for Research and Treatment of Cancer/Mycoses Study Group of the National Institute of Allergy and Infectious Diseases [17]. For probable and possible IFD, we considered host factors and major and minor criteria in determining the strength of the evidence supporting the diagnosis. Definite IFD required the demonstration of tissue-invasive mold on histological examination of tissue samples or the presence of fungemia in patients with clinical and/or radiographic evidence of deep-tissue infection. Isolation of Aspergillus and Penicillium species from a blood culture alone with no evidence of deep-tissue infection was regarded as pseudofungemia [18]. Adverse events were considered to be due to GM-CSF if attributed to the agent in notes by the treating physician, consulting physician, a mid-level healthcare provider and/or rounding pharmacy staff, or if discontinuation resulted in prompt resolution of symptoms. Patients were stratified into two groups: those who achieved complete or partial resolution of IFD and those in whom IFD did not improve or who showed clinical and/or radiographic progression. Infection-related death was defined as death within 12 weeks of the last positive culture among patients with microbiologically documented filamentous mold infections in the absence of known noninfectious causes of death. For patients with clinical and/or radiographic diagnosis of infection, infection-associated deaths were defined according to established guidelines [19].

\section{Statistical Analysis}

We calculated descriptive statistics for all patients and for those who did and who did not have a response to antifungal plus GM-CSF therapy. Differences in categorical data were analyzed using the $\chi^{2}$ test or the Fisher exact test, and differences in discrete variables were analyzed using Student's two-tailed t test; a p value $<0.05$ considered to be statistically significant. A backward logis- 
tic regression analysis model was used to identify factors predictive of treatment failure. We used PASW Statistics 18 software (2009; IBM ${ }^{\circledR}$ SPSS $^{\circledR}$ software, Somers, N.Y., USA) for all statistical analyses.

\section{Results}

Sixty-six patients with IFD received adjuvant GMCSF during the period studied. Patient, disease and treatment characteristics are summarized in table 1 . Ten patients had received high-dose systemic corticosteroids before GM-CSF therapy; the median cumulative dose (c.d.) \pm standard deviation was $1,184 \pm 1,019 \mathrm{mg}$ (range $338-3,540 \mathrm{mg}$ ), and the median duration was $30 \pm 16$ days (range 13-71 days). Nine patients received high-dose systemic corticosteroids during GM-CSF therapy; the median c.d. was $230 \pm 1,314 \mathrm{mg}$ (range $75-4,200 \mathrm{mg}$ ), and the median duration was $16 \pm 12$ days (range 2-30). The daily dose of GM-CSF was $500 \mu \mathrm{g}$ in $97 \%$ of patients; GM-CSF was given via subcutaneous injection in all cases. Thirty-five patients (53\%) had a response, whereas IFD-related deaths were noted mostly in 29 (94\%) of 31 patients who failed GM-CSF plus systemic antifungal therapy.

Table 2 summarizes the characteristics of infections among patients who did and did not have a response to antifungal plus adjuvant GM-CSF therapy. Causes of death are also given. It is interesting that 2 of 11 patients with proven zygomycosis and 2 of 7 patients with proven cutaneous and/or disseminated Fusarium spp. infection survived on long-term follow up; whereas all 4 with invasive aspergillosis had died.

Six patients had adverse events attributable to GMCSF administration: 3 patients had myalgia and individual patients had fever, localized skin rash and bone pain, respectively. In all these patients symptoms resolved following discontinuation of GM-CSF. There were no cases of pulmonary capillary leak syndrome or unexplained noncardiogenic pulmonary edema during GM-CSF treatment or during the following 12 weeks. All-cause deaths were observed in 44 patients (68\%) and 32 (48\%) patients died of progressive IFD.

\section{Univariate Analysis}

Patients in whom antifungal drug plus GM-CSF therapy failed were compared to those in whom a complete or partial response was observed (table 1). In patients who had comorbid medical conditions such as diabetes mellitus or renal failure, antifungal plus GM-CSF therapy was significantly more likely to fail (74 vs. $49 \%$; $\mathrm{p} \leq 0.04$ ). Similarly, high-dose corticosteroid therapy prior to GMCSF use was significantly associated with treatment failure ( 29 vs. $3 \% ; \mathrm{p} \leq 0.004)$. Patients with proven/probable IFD ( 84 vs. $54 \%$; $\mathrm{p} \leq 0.01$ ) and those in whom GM-CSF therapy commenced during an intensive care unit stay (35 vs. $6 \%$; $\mathrm{p} \leq 0.04$ ) were significantly more likely to have treatment failure. Furthermore, patients in whom therapy failed required longer hospitalization (median 35 \pm 27 vs. $25 \pm 18$ days; $\mathrm{p} \leq 0.03$ ) and were more likely to die of any cause (100 vs. $37 \%$; $\mathrm{p} \leq 0.0001)$ or of IFD (94 vs. $9 \% ; \mathrm{p} \leq 0.0001)$. Patients who had a favorable response were more likely to have received antineoplastic chemotherapy prior to GM-CSF use (86 vs. $61 \%$; $\mathrm{p} \leq$ 0.02 ) and less likely to have received granulocyte transfusions ( 31 vs. $58 \%$; $\mathrm{p} \leq 0.03$ ). There were no differences between responders and nonresponders for other factors typically associated with poor treatment outcomes, including refractory cancer, allogeneic stem cell transplant, severe neutropenia, lymphocytopenia, high APACHE II score or concurrent therapy with granulocyte colonystimulating factor and/or IFN- $\gamma$ (table 1).

\section{Multivariate Analysis}

The results of logistic regression analysis for the factors associated with therapeutic failure are shown in table 3. The use of high-dose systemic corticosteroids prior to GM-CSF therapy (OR 24; 95\% CI 2.21-264.9; $\mathrm{p} \leq$ 0.009), GM-CSF therapy initiated during an intensive care unit stay (OR 10; 95\% CI 1.66-63.8; $\mathrm{p} \leq 0.01$ ) and proven or probable IFD (OR 4; 95\% CI 1-16.2; p $\leq$ 0.05 ) were independently predictive of treatment failure. In addition, a five-fold higher probability of treatment failure was seen among the 29 patients who had received healthy-donor granulocyte transfusions (OR 5; 95\% CI 1.27-16.8; $\mathrm{p} \leq 0.02$ ); this finding was unexpected.

\section{Discussion}

In this analysis, GM-CSF was well tolerated without serious toxic effects in severely immunosuppressed patients who often received prolonged therapy (up to 57 doses). A complete or partial response occurred in more than half of the patients despite recent treatment with antineoplastic therapy. Initiation of GM-CSF therapy in critically ill patients did not improve outcomes significantly. Similarly, patients with medical comorbidities treated with GM-CSF plus antifungal drugs had higher rates of treatment failure. 
Table 1. Characteristics of patients treated with adjuvant GM-CSF for IFD, by response to antifungal treatment

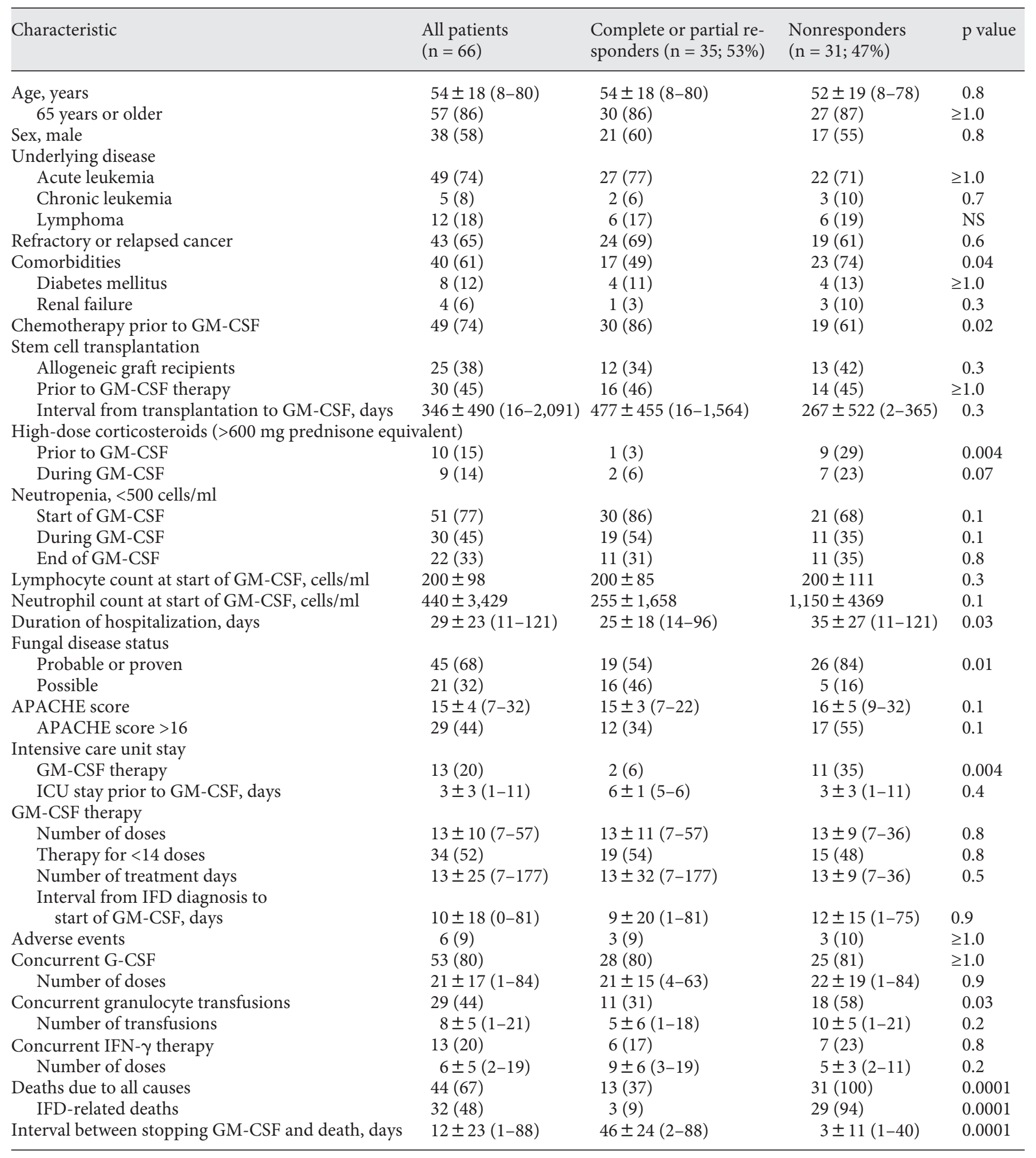

Data are presented as number of patients (\%) or median value \pm standard deviation (range). G-CSF $=$ Granulocyte colony-stimulating factor. 
Table 2. Characteristics of infections, treatment outcomes and results of extended follow-up in patients treated with adjuvant GM-CSF for IFD

\begin{tabular}{|c|c|c|c|}
\hline Infection characteristics & $\begin{array}{l}\text { Complete or partial } \\
\text { responders }(n=35)\end{array}$ & $\begin{array}{l}\text { Nonresponders } \\
(\mathrm{n}=31)\end{array}$ & Cause of death $(n=44)$ \\
\hline Possible fungal infection & $16(46)$ & $5(16)$ & $10(23)$ \\
\hline Fungal pneumonia and parainfluenza 3 pneumonitis & $1(3)$ & 0 & $\begin{array}{l}\text { Adult respiratory distress } \\
\text { syndrome }\end{array}$ \\
\hline $\begin{array}{l}\text { Fungal pneumonia, MRSA bacteremia and parainfluenza } 3 \\
\text { upper respiratory tract infection }\end{array}$ & 0 & $1(3)$ & $\begin{array}{l}\text { Graft-versus-host disease and } \\
\text { progressive pneumonia }\end{array}$ \\
\hline $\begin{array}{l}\text { Fungal pneumonia and RSV upper respiratory tract } \\
\text { infection }\end{array}$ & $1(3)$ & 0 & \\
\hline Probable fungal infection & $8(23)$ & $10(32)$ & $11(25)$ \\
\hline Aspergillus terreus pneumonia & $1(3)$ & 0 & \\
\hline Aspergillus flavus pneumonia & 0 & $1(3)$ & Progressive fungal pneumonia \\
\hline $\begin{array}{l}\text { Aspergillus spp. pneumonia, disseminated adenovirus } \\
\text { infection to lungs and bone marrow }\end{array}$ & 0 & $1(3)$ & $\begin{array}{l}\text { Relapsed malignancy and } \\
\text { progressive infection }\end{array}$ \\
\hline $\begin{array}{l}\text { Aspergillus flavus and Stenotrophomonas maltophilia } \\
\text { pneumonia }\end{array}$ & 0 & $1(3)$ & $\begin{array}{l}\text { Progressive polymicrobial } \\
\text { pneumonia }\end{array}$ \\
\hline $\begin{array}{l}\text { Aspergillus niger pneumonia, Enterococcus faecalis } \\
\text { pneumonia and bacteremia, and CoNS bacteremia }\end{array}$ & 0 & $1(3)$ & $\begin{array}{l}\text { Progressive polymicrobial } \\
\text { pneumonia }\end{array}$ \\
\hline $\begin{array}{l}\text { Aspergillus fumigatus pneumonia and parainfluenza } 3 \\
\text { pneumonia }\end{array}$ & $1(3)$ & 0 & \\
\hline Aspergillus versicolor and Enterococcus spp. pneumonia & 0 & $1(3)$ & Progressive pneumonia \\
\hline Alternaria spp. and Curvularia spp. sinusitis & $1(3)$ & 0 & \\
\hline Mucor spp. pneumonia & $1(3)$ & 0 & \\
\hline Mucor spp. and Enterococcus spp. pneumonia & 0 & $1(3)$ & Progressive fungal pneumonia \\
\hline Proven fungal infection & $11(31)$ & $16(52)$ & $23(52)$ \\
\hline Candida krusei fungemia and RSV pneumonitis & 0 & $1(3)$ & Refractory RSV pneumonitis \\
\hline Fusarium spp. sinusitis and Aspergillus flavus fungemia & 0 & $1(3)$ & $\begin{array}{l}\text { Relapsed malignancy and } \\
\text { progressive infection }\end{array}$ \\
\hline $\begin{array}{l}\text { Aspergillus fumigatus cerebral abscess, pulmonary } \\
\text { zygomycosis, adenovirus cystitis }\end{array}$ & 0 & $1(3)$ & $\begin{array}{l}\text { Graft failure and progressive } \\
\text { fungal disease }\end{array}$ \\
\hline $\begin{array}{l}\text { Aspergillus fumigatus pneumonia, Alternaria spp. sinusitis, } \\
\text { VRE pneumonia }\end{array}$ & 0 & $1(3)$ & $\begin{array}{l}\text { Graft-versus-host disease and } \\
\text { progressive fungal disease }\end{array}$ \\
\hline Aspergillus terreus pneumonia & $1(3)$ & $1(3)$ & $\begin{array}{l}\text { Relapsed malignancy plus } \\
\text { progressive infection }\end{array}$ \\
\hline
\end{tabular}


Table 2 (continued)

Infection characteristics

Candida tropicalis disseminated disease, Roseomonas spp., 1 (3)

CoNS, Stomatococcus spp., and alpha Streptococcus

bacteremia

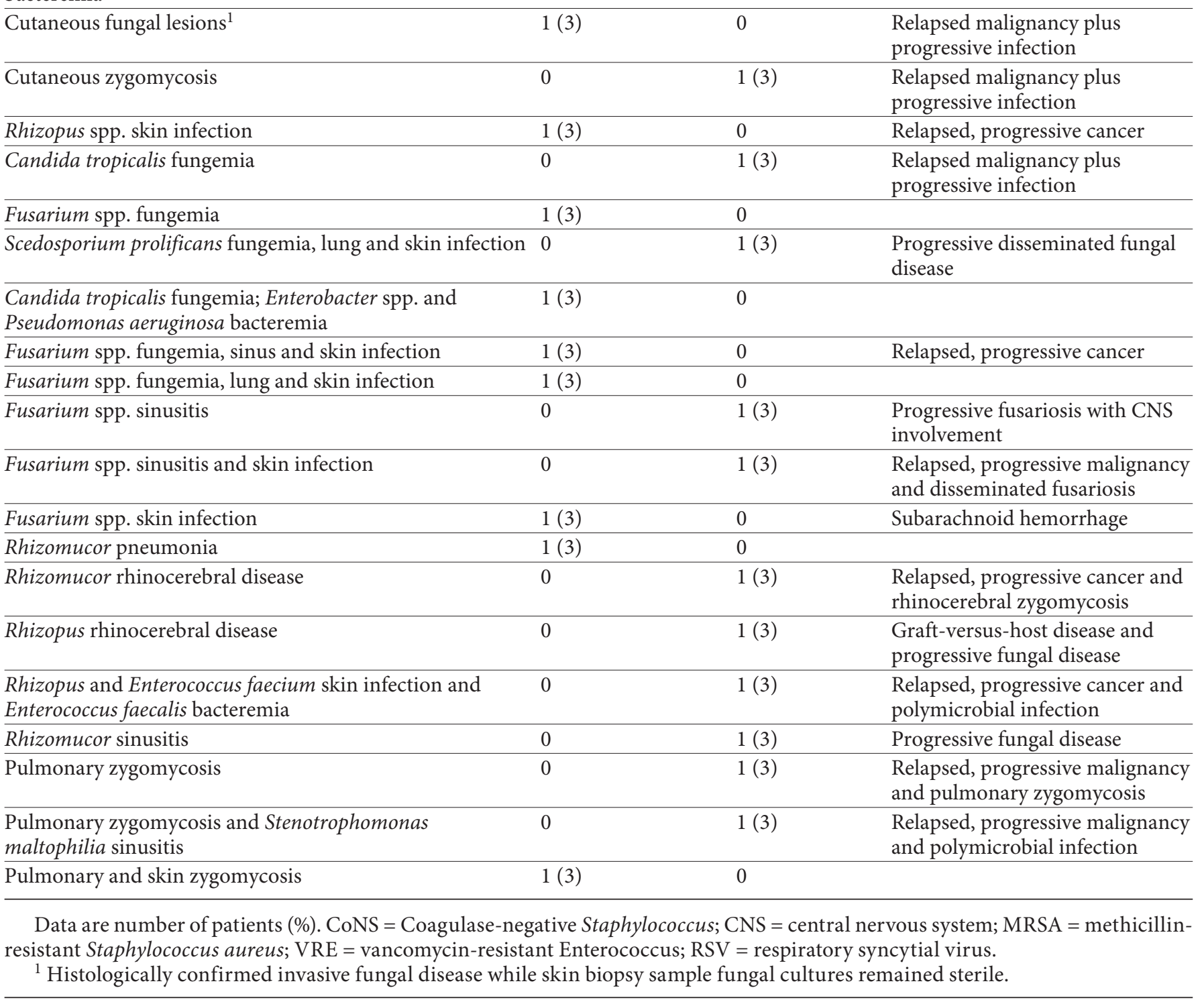

Complete or partial Nonresponders Cause of death $(n=44)$ responders $(\mathrm{n}=35) \quad(\mathrm{n}=31)$
0 
Table 3. Multivariate analysis of factors predictive of treatment failure in patients who received adjuvant GMCSF for IFD

\begin{tabular}{lrcc}
\hline Factor associated with failure & OR & $95 \%$ CI & p value \\
\hline Steroid use prior to GM-CSF & 24 & $2.21-264.9$ & 0.009 \\
Intensive care unit at start of GM-CSF & 10 & $1.66-63.8$ & 0.01 \\
Granulocyte transfusion during GM-CSF & 5 & $1.27-16.8$ & 0.02 \\
Proven or probable IFD & 4 & $1-16.2$ & 0.05 \\
\hline
\end{tabular}

riously ill patients with prolonged, severe neutropenia [20] or unappreciated adverse events from the granulocyte transfusions, and possible reactivation of opportunistic herpes viruses such as human herpes virus 6 , which was recently shown to be associated with granulocyte transfusions [21].

Significantly better outcome in patients presented in this study who recently received antineoplastic therapy may in part reflect early myeloid recovery associated with recombinant myeloid growth factor [22]. In a large multicenter trial, patients who were randomized to receive GM-CSF supportive therapy exhibited a median overall survival advantage of nearly 6 months. Patients treated with adjuvant GM-CSF also demonstrated an earlier neutrophil recovery, had fewer episodes of serious infections including fungal infections, and, importantly, experienced fewer infection-associated deaths in comparison with patients with no myeloid recovery support [22]. However, this benefit was not seen in a subsequent, albeit smaller, single-center trial [23]. More recently, in a matched-cohort study of nearly 2,000 health insurance claims in the USA from 2000 to 2007 , GM-CSF recipients demonstrated a $56 \%$ lower risk of infection-related hospitalizations compared to patients treated with short- or long-acting granulocyte colony-stimulating factor [24].

In animal experiments, GM-CSF mitigates corticosteroid-induced suppression of proinflammatory cytokines such as interleukin-1 and tumor necrosis factor-alpha and chemotactic chemokines such as macrophage inflammatory protein-1-alpha by bronchoalveolar macrophages that are pivotal in early innate defenses against disease-causing Aspergillus microconidia [25]. Reversal of corticosteroid-induced macrophage suppression following GM-CSF exposure has been demonstrated to last for a week or longer in animal experiments [25]. Dexamethasone promotes $\kappa \mathrm{B}$ inhibitor levels in the cytoplasm of macrophages; this blocks nuclear factor- $\kappa \mathrm{B}$ translocation to the nucleus. GM-CSF reduces the cytoplasmic concentration of inhibitor $\kappa \mathrm{B}$, resulting in high NF- $\mathrm{B}$ concentrations in macrophage nuclei thereby augmenting innate microbicidal activity [26]. The clinical relevance of these findings gathered from experiments in nonprimate vertebrates remains unclear. In our study, $15 \%$ of patients had been exposed to high-dose systemic corticosteroids prior to and 14\% during GM-CSF therapy. It was expected from the above findings that GM-CSF adjuvant therapy would improve outcomes for this subgroup of patients with fungal disease; however, on multivariate analysis, exposure to high-dose steroids remained the most prominent predictor of treatment failure despite GM-CSF therapy (table 3). This observation was unexpected and requires a further assessment of alternative mechanism(s) for GM-CSF-based immune modulation in patients with IFD. Impact on GM-CSF on other innate effector cells such as natural killer (NK) cells had also been demonstrated to promote fungicidal activity and reverse the immunosuppressive effect of fungi on NK cells [27]. A thorough analysis of innate immune function following GM-CSF therapy in relationship to IFD outcome is needed.

Alternative routes of cytokine administration have been studied to reduce systemic exposure and potential of unintended consequences such as leukemia stimulation and exacerbation of graft-versus-host disease. As the majority of fungal infections involve the lungs, aerosolized drug delivery has been considered an attractive platform for drug administration. In a recent study, high drug concentrations were achieved in lung tissue and undesired systemic exposure was prevented with aerosol GM-CSF delivery, resulting in low potential drug toxicity and drug-drug interactions [28]. In other experiments, intranasal GM-CSF resulted in a six-fold decrease in fungal burden among immunosuppressed mice in an experimental model of pulmonary necrotizing aspergillosis [29]. The safety and feasibility of aerosolized GM-CSF for metastatic disease have been evaluated in patients with respiratory tract malignancies [30] but need further evaluation for the treatment of pulmonary mycosis. 
As with all retrospective studies, heterogeneity introduced by patient selection, dose and route of administration, various levels of immunosuppression due to underlying disease and type and number of antineoplastic therapies, various preparatory regimens for allogeneic stem cell transplantation, and the use of other myeloid growth factors (e.g. granulocyte colony-stimulating factor, IFN$\gamma)$ and a large cohort of patients with possible rather than probable or definite IFD may influence outcomes. However, in the cohort presented, the subgroups of patients who did and did not have a response showed no significant differences in the distribution of refractory cancer, allogeneic stem cell transplantation, presence of severe neutropenia or lymphocytopenia, severity of illness and multiorgan dysfunction as measured by APACHE II score, or concurrent use of other cytokines to promote neutrophil recovery or cellular immune responses (table 1). Furthermore, this is the largest study reported so far on GM-CSF use in patients with established IFD.

In summary, this large patient cohort provides comprehensive information regarding the tolerability of modern recombinant GM-CSF preparations (sargramostim) and the feasibility of administering the agent to high-risk cancer patients and stem cell transplant recipients with IFD. It was unexpected that, despite the addition of GM-CSF, high-dose systemic corticosteroid therapy continued to remain a prominent predictor of treatment failure. A complete or partial response occurred in more than half of the patients treated with GM-CSF despite recent treatment with antineoplastic therapy and the presence of other predictors of poor outcome. Further prospective studies to assess GM-CSF efficacy in the treatment of established fungal disease are needed.

\section{Acknowledgments}

This study was supported by a core grant (CA16672) to the University of Texas MD Anderson Cancer Center from the National Cancer Institute and National Institutes of Health.

We are grateful to Dr. Judith Aberg of NYU School of Medicine for her insightful editorial comments.

\section{References}

1 Safdar A: Difficulties with fungal infections in acute myelogenous leukemia patients: immune enhancement strategies. Oncologist 2007;12(suppl 2):2-6.

$\checkmark 2$ Safdar A: Strategies to enhance immune function in hematopoietic transplantation recipients who have fungal infections. Bone Marrow Transplant 2006;38:327-337.

$>3$ Safdar A: Immunomodulation therapy for invasive aspergillosis: discussion on myeloid growth factors, recombinant cytokines and antifungal drug immune modulation. Curr Fungal Infect Rep 2010;4:1-7.

$\checkmark 4$ Roilides E, Holmes A, Blake C, Venzon D, Pizzo PA, Walsh TJ: Antifungal activity of elutriated human monocytes against Aspergillus fumigatus hyphae: enhancement by granulocyte-macrophage colony-stimulating factor and interferon-gamma. J Infect Dis 1994; 170:894-899.

$\checkmark 5$ Roilides E, Blake C, Holmes A, Pizzo PA, Walsh TJ: Granulocyte-macrophage colonystimulating factor and interferon-gamma prevent dexamethasone-induced immunosuppression of antifungal monocyte activity against Aspergillus fumigatus hyphae. J Med Vet Mycol 1996;34:63-69.
-6 Gil-Lamaignere C, Simitsopoulou M, Roilides E, Maloukou A, Winn RM, Walsh TJ: Interferon-gamma and granulocyte-macrophage colony-stimulating factor augment the activity of polymorphonuclear leukocytes against medically important zygomycetes. J Infect Dis 2005;191:1180-1187.

7 Rodríguez MM, Calvo E, Mariné M, Pastor FJ, Fernandez-Ballart J, Guarro J: Efficacy of liposomal amphotericin B combined with gamma interferon or granulocyte-macrophage colony-stimulating factor for treatment of systemic zygomycosis in mice. Antimicrob Agents Chemother 2009;53:35693571 .

-8 Lamaris GA, Chamilos G, Lewis RE, Safdar A, Raad II, Kontoyiannis DP: Scedosporium infection in a tertiary care cancer center: a review of 25 cases from 1989-2006. Clin Infect Dis 2006;43:1580-1584.

-9 Safdar A, Papadopoulos EB, Young JW: Breakthrough Scedosporium apiospermum (Pseudallescheria boydii) brain abscess during therapy for invasive pulmonary aspergillosis following high-risk allogeneic hematopoietic stem cell transplantation. Scedosporiasis and recent advances in antifungal therapy. Transpl Infect Dis 2002;4:212-217.

10 Roilides E, Simitsopoulou M, Katragkou A, Walsh TJ: Host immune response against Scedosporium species. Med Mycol 2009;47: 433-440.
11 Lewis R, Hogan H, Howell A, Safdar A: Progressive fusariosis: unpredictable posaconazole bioavailability, and feasibility of recombinant interferon-gamma plus granulocyte macrophage-colony stimulating factor for refractory disseminated infection. Leuk Lymphoma 2008;49:163-165.

12 Abzug MJ, Walsh TJ: Interferon-gamma and colony-stimulating factors as adjuvant therapy for refractory fungal infections in children. Pediatr Infect Dis J 2004;23:769-773.

13 Bandera A, Trabattoni D, Ferrario G, Cesari M, Franzetti F, Clerici M, Gori A: Interferongamma and granulocyte-macrophage colony stimulating factor therapy in three patients with pulmonary aspergillosis. Infection 2008;36:368-373.

14 Dignani MC, Rex JH, Chan KW, Dow G, de Magalhaes-Silverman M, Maddox A, Walsh T, Anaissie E: Immunomodulation with interferon-gamma and colony-stimulating factors for refractory fungal infections in patients with leukemia. Cancer 2005;104:199204

15 Bodey GP, Anaissie E, Gutterman J, VadhanRaj S: Role of granulocyte-macrophage colony-stimulating factor as adjuvant therapy for fungal infection in patients with cancer. Clin Infect Dis 1993;17:705-707. 
16 Safdar A, Rodriguez GH, Lichtiger B, Dickey BF, Kontoyiannis DP, Freireich EJ, Shpall EJ, Raad II, Kantarjian HM, Champlin RE: Recombinant interferon $\gamma 1 \mathrm{~b}$ immune enhancement in 20 patients with hematologic malignancies and systemic opportunistic infections treated with donor granulocyte transfusions. Cancer 2006;106:2664-2671.

-17 Ascioglu S, Rex JH, de Pauw B, Bennett JE, Bille J, Crokaert F, Denning DW, Donnelly JP, Edwards JE, Erjavec Z, Fiere D, Lortholary O, Maertens J, Meis JF, Patterson TF, Ritter J, Selleslag D, Shah PM, Stevens DA, Walsh TJ, Invasive Fungal Infections Cooperative Group of the European Organization for Research and Treatment of Cancer, Mycoses Study Group of the National Institute of Allergy and Infectious Diseases: Defining opportunistic invasive fungal infections in immunocompromised patients with cancer and hematopoietic stem cell transplants: an international consensus. Clin Infect Dis 2002;34:7-14.

-18 Safdar A, Singhal S, Mehta J: Clinical significance of non-Candida fungal blood isolation in patients undergoing high-risk allogeneic hematopoietic stem cell transplantation (1993-2001). Cancer 2004;100:2456-2461.

19 Safdar A, Rodriguez GH, De Lima MJ, Petropoulos D, Chemaly RF, Worth LL, Shpall EJ, Rolston KV, Raad II, Chan KW, Champlin RE: Infections in 100 cord blood transplantations: spectrum of early and late posttransplant infections in adult and pediatric patients 1996-2005. Medicine 2007;86:324333.
20 Safdar A, Hanna HA, Boktour M, Kontoyiannis DP, Hachem R, Lichtiger B, Freireich EJ, Raad II: Impact of high-dose granulocyte transfusions in patients with cancer with candidemia: retrospective case-control analysis of 491 episodes of Candida species bloodstream infections. Cancer 2004; 101: 2859-2865.

21 Chemaly RF, Torres HA, Hachem R, Kontoyiannis DP, Safdar A, Raad II: Human herpesvirus-6 DNAemia in immunosuppressed adult patients with leukemia at risk for mold infection. Haematologica 2008;93:157-158.

22 Rowe JM, Andersen JW, Mazza JJ, Bennett JM, Paietta E, Hayes FA, Oette D, Cassileth PA, Stadtmauer EA, Wiernik PH: A randomized placebo-controlled phase III study of granulocyte-macrophage colony-stimulating factor in adult patients ( $>55$ to 70 years of age) with acute myelogenous leukemia: a study of the Eastern Cooperative Oncology Group (E1490). Blood 1995;86:457-462.

23 Verbeek W, Wörmann B, Koch P, Aul C, Hinrichs HF, Balleisen L, Rowe JM, Bennett J, Haase D, Fonatsch C, Heinecke A, Büchner T, Hiddemann W: Results of a randomized double-blind placebo-controlled trial evaluating sequential high-dose cytosine arabinoside/mitoxantrone chemotherapy with or without granulocyte/macrophage-colonystimulating factor in high-risk myelodysplastic syndromes. J Cancer Res Clin Oncol 1999;125:369-374.

24 Heaney ML, Toy EL, Vekeman F, Laliberté F, Dority BL, Perlman D, Barghout V, Duh MS: Comparison of hospitalization risk and associated costs among patients receiving sargramostim, filgrastim, and pegfilgrastim for chemotherapy-induced neutropenia. Cancer 2009;115:4839-4848.
25 Brummer E, Kamberi M, Stevens DA: Regulation by granulocyte-macrophage colonystimulating factor and/or steroids given in vivo of proinflammatory cytokine and chemokine production by bronchoalveolar macrophages in response to Aspergillus conidia. J Infect Dis 2003;187:705-709.

-26 Choi JH, Brummer E, Kang YJ, Jones PP, Stevens DA: Inhibitor $\kappa B$ and nuclear factor $\kappa B$ in granulocyte-macrophage colony-stimulating factor antagonism of dexamethasone suppression of the macrophage response to Aspergillus fumigatus conidia. J Infect Dis 2006;193:1023-1028.

27 Schmidt S, Tramsen L, Hanisch M, Latgé JP, Huenecke S, Koehl U, Lehrnbecher T: Human natural killer cells exhibit direct activity against Aspergillus fumigatus hyphae, but not against resting conidia. J Infect Dis 2011; 203:430-435

28 Safdar A, Shelburne SA, Evans SE, Dickey BF: Inhaled therapeutics for prevention and treatment of pneumonia. Expert Opin Drug Saf 2009;8:435-449.

29 Quezada G, Koshkina NV, Zweidler-McKay P, Zhou Z, Kontoyiannis DP, Kleinerman ES: Intranasal granulocyte-macrophage colonystimulating factor reduces the Aspergillus burden in an immunosuppressed murine model of pulmonary aspergillosis. Antimicrob Agents Chemother 2008;52:716-718.

30 Rao RD, Anderson PM, Arndt CA, Wettstein PJ, Markovic SN: Aerosolized granulocyte macrophage colony-stimulating factor (GM$\mathrm{CSF}$ ) therapy in metastatic cancer. Am J Clin Oncol 2003;26:493-498. 